\title{
Detection of capsular genotypes of methicillin-resistant Staphylococcus aureus and clonal distribution of the cap5 and cap8 genes in clinical isolates
}

\author{
Gabriela Echániz-Aviles ${ }^{1}$ Maria Elena Velazquez-Meza ${ }^{1}$ • B Brian Rodríguez-Arvizu ${ }^{1}$. \\ Maria Noemi Carnalla-Barajas ${ }^{1} \cdot$ Araceli Soto Noguerón $^{1}$
}

Received: 3 January 2022 / Revised: 22 January 2022 / Accepted: 3 February 2022 / Published online: 21 February 2022

(c) The Author(s), under exclusive licence to Springer-Verlag GmbH Germany, part of Springer Nature 2022

\begin{abstract}
Up until now, the capsular polysaccharides of Staphylococcus aureus have been classified into 11 types, of which only 2 types 5 and 8; (encoded by the genes cap5 and cap8, respectively) are present in 80-90\% of clinically significant strains. The aim of the present study was to detect the capsular genotypes of methicillin-resistant $S$. aureus (MRSA) clinical isolates and determined their clonal distribution. A total of 262 MRSA clinical isolates from different hospitals in Mexico were analyzed by PCR to determine the genetic characteristics of their capsule expression. Pulsed-field gel electrophoresis and multilocus sequence typing were used to characterize the isolates. The analysis of the capsular genotypes among MRSA isolates showed that 245 isolates $(93.5 \%)$ contained the cap5 gene, and that the remaining 17 (6.5\%) encoded the cap 8 gene. The MRSA isolates were grouped into four clonal groups. The identification of the capsular genotypes of clinical isolates of MRSA is important information because potential vaccine formulations against $S$. aureus involve capsular polysaccharides.
\end{abstract}

Keywords MRSA $\cdot$ Capsular genotypes $\cdot$ Clinical isolates $\cdot \operatorname{cp} 5 \cdot \operatorname{cp} 8$

\section{Introduction}

Methicillin-resistant Staphylococcus aureus (MRSA) is a major cause of both hospital and community-associated infections worldwide (Kateete et al. 2019; Khalid et al. 2018; Harada et al. 2018). The ability of MRSA to cause a variety of infections is due to the expression of multiple virulence factors, including adhesins, cytotoxins, superantigens and exoenzymes, as well as capsular polysaccharides, all of which contribute to the pathogenesis of staphylococcal infections (Haddad et al. 2018). The capsular polysaccharide (CP) is a bacterial cell wall component that protects bacteria from phagocytosis and enhances microbial virulence. The CP prevents the activity of neutrophils against bacteria,

Communicated by Erko Stackebrandt.

Maria Elena Velazquez-Meza

mevelaz@insp.mx

1 Centro de Investigación sobre Enfermedades Infecciosas, Instituto Nacional de Salud Pública, Universidad 655, Cerrada de los Pinos y Caminera, Col. Sta. María Ahuacatitlán, CP 62100 Cuernavaca, Morelos, Mexico preventing chemotaxis and phagocytosis and promoting cell adhesion to prosthetic devices. Up until now, the CP of $S$. aureus have been classified into 11 types, of which only 2 types 5 and 8; (encoded by the genes cap5 and cap8, respectively) are present in 80-90\% of clinically significant strains (Keinhörster et al. 2019; Melles et al. 2008; Rozemeijer et al. 2015). Serotypes 5 and 8 have similar trisaccharide repeating units comprised of $N$-acetyl mannosaminuronic acid, $N$-acetyl L-fucosamine, and $N$-acetyl D-fucosamine (Visansirikul et al. 2020). Although the majority of $S$. aureus isolates are type 5 or 8 , the remaining $10-20 \%$ of the clinical strains, which are nontypeable, are denominated as antigen 336 (Ag336). The 336 antigens also name polysaccharide 336 (PS336) was purified from a strain deposited at ATCC under number ATCC 55,804 and used to serotype S. aureus isolates that do not produce capsule (Verdier et al. 2007).

Methicillin resistance is conferred to $S$. aureus strains by the presence of a mobile genetic element called the staphylococcal cassette chromosome mec (SCCmec), which carries the mecA gene. At least 13 types of SCCmec elements have been identified. Different MRSA clones have been observed among epidemic MRSA isolates. Perhaps successful lineages of epidemic MRSA clones have an adaptive advantage 
due to their antibiotic resistance and virulence (Lakhundi and Zhang 2018; Challagundla et al. 2018). One strategy for the prevention of staphylococcal infections is the formulation of vaccines, in which CP play an important role. Specific antibodies against CP5 and CP8 have been shown to be protective against $S$. aureus infections (Park et al. 2014; Inouea et al. 2018). The aim of the present study was to detect the capsular genotypes of MRSA clinical isolates and determined their clonal distribution.

\section{Material and methods}

\section{Bacterial isolates}

Isolates identified as MRSA collected during a 14-year (1999-2012) period were analyzed in this study. These strains were recovered from seven different hospitals in Mexico; three of them located in Mexico City (H1, H2, and H3), two in the north of the country (H4, H5), one in the south (H6), and the other in the west (H7). All strains were recovered from single patients and of different sources: abscess, bronchial aspirate, blood, wound infections, cerebrospinal fluid, pleural fluid, soft tissue, catheter, sputum, and others sources.

\section{DNA extraction}

The strains were grown for $18 \mathrm{~h}$ at $37{ }^{\circ} \mathrm{C}$ on tryptic soy agar plates (Difco, Oxoid, Hampshire, United Kingdom). One colony of each strain was grown in tryptic soy broth for $17 \mathrm{~h}$ at $37^{\circ} \mathrm{C}$. Genomic DNA was extracted using the Wizard Genomic DNA Purification Kit (Promega, Corporation, Madison WI, USA) following the manufacturer's instructions.

\section{Detection of capsular genotypes}

Genomic DNA was used for PCR amplification with primers cap5-1 (5'-GGTTTGCTGAAAAACCAGTC- $\left.3^{\prime}\right)$ and cap5-2 (5'-CCTCATATGCTCCTACATTT-3'), as well as the primers cap8-1 (5'-GCGCTACAAACATTAAGC AT-3') and cap8-2 (5'-TTCTTAGCCTGCTGGCATC-3'). The amplification was carried out in an Eppendorf thermocycler (Eppendorf, Scientific Inc. Hauppauge, NY) under the following conditions: an initial 4-min denaturation step at $94{ }^{\circ} \mathrm{C}$, followed by 25 cycles of $20 \mathrm{~s}$ of denaturation at $94{ }^{\circ} \mathrm{C}, 20 \mathrm{~s}$ of annealing at $50{ }^{\circ} \mathrm{C}$, and $50 \mathrm{~s}$ of extension at $72{ }^{\circ} \mathrm{C}$, with a final extension step at $72{ }^{\circ} \mathrm{C}$ for $10 \mathrm{~min}$ (Sau et al. 1997). PCR products were analyzed by electrophoresis on ethidium bromide-stained $1.5 \%$ agarose gels (SigmaAldrich. Lyon, France). The sizes of the amplicons were $185 \mathrm{bp}$ for capsular type 5 and $170 \mathrm{bp}$ for capsular type 8 .
The control strains ATCC49521 (cap5) and ATCC 49,525 (cap8) were included in each assay.

\section{Pulsed-field gel electrophoresis (PFGE)}

Whole-genomic DNA was prepared as described previously (Chung et al. 2000). After digestion with SmaI endonuclease, DNA was separated in a CHEF-DRII apparatus (BioRad, Birmingham, United Kingdom). The control strains EMRSA16, HPV107 (Iberian), BK2464 (New York-Japan) and USA300, were included in the PFGE gels for comparison. These strains were kindly provided by Prof. Herminia de Lencastre from the Molecular Genetic Laboratory at the Instituto de Tecnologia Quımica e Biologica da Universidade Nova de Lisboa. We used the criteria of Tenover et al. to compare different clones (Tenover et al. 1995).

\section{SCCmec typing and multilocus sequence typing (MLST)}

Strains representatives of each clone, throughout the study period, were characterized by SCCmec typing and MLST. The multiplex PCR for mec element type was performed according to Oliveira, this included eight loci (A through $\mathrm{H})$ and an internal positive control ( $m e c A$ gene) (Oliveira and Lencastre 2002). The MLST was performed according to Enright, the sequences of internal fragments of seven housekeeping genes were amplified by PCR: carbamate kinase $(\operatorname{arcC})$, shikimate dehydrogenase ( $\operatorname{aroE})$, glycerol kinase $(g l p)$, guanylate kinase $(g m k)$, phosphate acetyltransferase ( $p t a)$, triosephosphate isomerase (tpi), and acetyl coenzyme A acetyltransferase (yqiL) (Enright et al. 2000). The assignment of alleles and sequence types (ST) was performed using the MLST data base (http://www.mlst.net) and eBURST analysis was performed.

\section{Results}

A total of 262 MRSA clinical isolates from different hospitals in Mexico were analyzed by PCR to determine the genetic and epidemiological characteristics of their capsule expression, specifically in genotypes 5 and 8 , to which most human $S$. aureus isolates belong to. These isolates were obtained from various body sites associated with $S$. aureus infections. The most common sources of isolates were blood (63/24\%), wound infections (52/19.8\%), soft tissue (38/14.5\%) and bronchial aspirate (30/11.5\%); the remaining (79/30.2\%) were obtained from ten different sources.

The analysis of the capsular genotypes among MRSA isolates showed that 245 isolates $(93.5 \%)$ contained the gene for CP type 5 (cap5), and that the remaining $17(6.5 \%)$ encoded the gene for CP type 8 (cap8). The 
distribution of cap 8 gene decreased across time; MRSA strains type 8 were detected in isolates from 1999 to 2002, (16/17) in two hospitals (H1 and H3), while only one strain $(173-\mathrm{H} 2)$ isolated in 2010 showed the cap 8 gene, these three hospitals are located in Mexico City. MRSA strains containing the cap 5 gene were present in isolates from all the years under consideration (1999-2012) and in the seven participating hospitals distributed in the center, north, south and west of the country.

The genotyping results demonstrated that there is an association between capsular serotypes and the results obtained by PFGE, SCCmec and MLST; thus, MRSA isolates were grouped into four clonal groups: ST5-MRSA-IINew York-Japan, ST8-MRSA-IV-USA300, ST247-MRSAI-Iberian and ST36-MRSA-II-EMRSA-16 clones. Two hundred and thirty-five of the 262 strains belonged to the ST5-MRSA-II-New York-Japan clone, and these isolates carried the cap5 gen; two clonal groups (ST8-MRSAIV-USA300 and ST247-MRSA-I-Iberian) and the strains with atypical patterns also carried the cap 5 gene, while the cap 8 gene was only associated with the ST36-MRSAII -EMRSA-16 clone (Fig. 1). All strains were analyzed by PFGE. The PFGE patterns of representative strains of the clones detected in this study and the profiles of control strains are shown in Fig. 2. Graphical presentation of multilocus sequence typing data by ST5 (majority clone) and ST8 (community clone) was performed for eBURST Fig. 3.

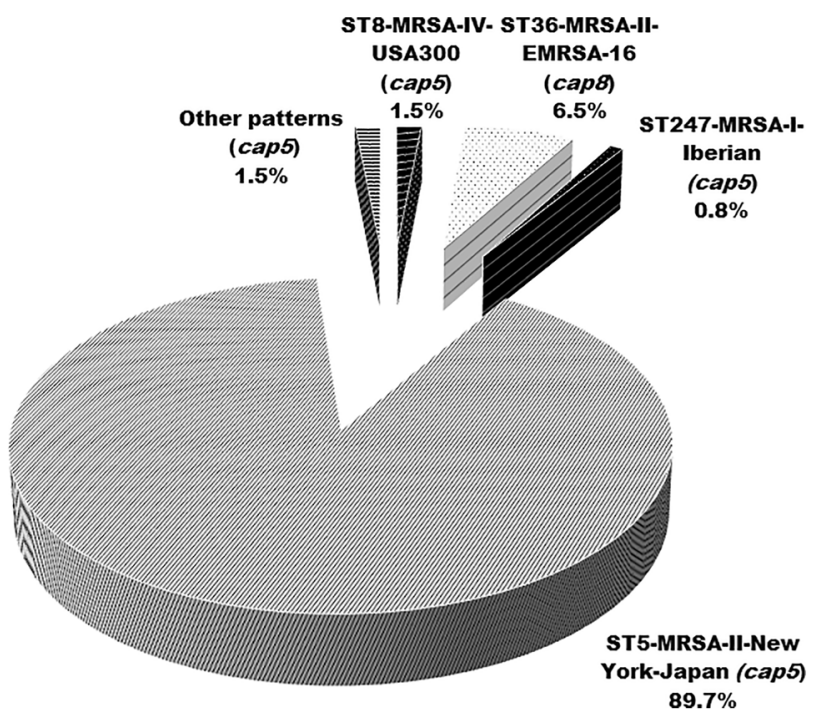

Fig. 1 Distribution of capsule genotypes (cap5 and cap8) among MRSA clinical isolates

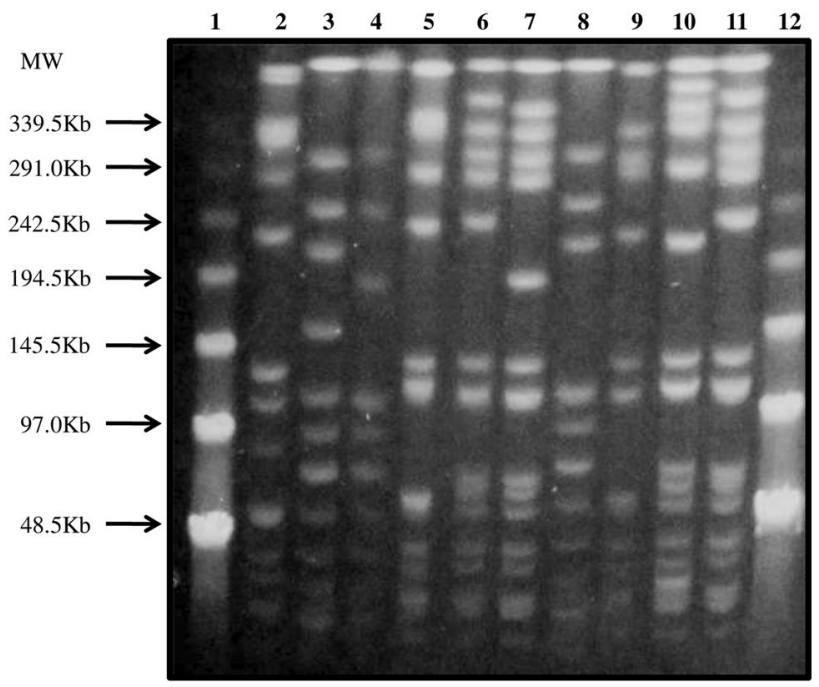

Fig. 2 Examples of pulsed field gel electrophoresis profiles obtained for MRSA clones of clinical isolates and international clones. Lanes 1 and 12 lambda ladder used a molecular size (MW) markers, 2-4 representatives clinical isolates of clones EMRSA-16, lines 5-7 New York-Japan, Iberian and USA300 clones, respectively. Lanes 8-11 control strains EMRSA16, BK2464, HPV107 and USA300

\section{Discussion}

This study was carried to characterize the genotypes of capsular polysaccharide expression in MRSA isolates from diverse clinical sources in seven hospitals in Mexico. The results showed that the majority of MRSA isolates (93.5\%) contained the cap5 gene, while a lower percentage contained the cap 8 gene. These results are in agreement with previous studies that reported a predominance of the serotype 5 among MRSA isolates (Verdier et al. 2007; Fournier et al. 1987; Mohamed et al. 2019). The distribution of CP has been analyzed in others countries around the world and the percentages of distribution vary at each study. In a study performed in 2016, in Kuwait 42 (3.1\%) S. aureus strains were reported to be CP8 (Udo et al. 2020). Liu in 2018 reported that Eighty-one strains (56.64\%) were Cap5, 36 strains $(25.17 \%)$ were identified as Cap8 type, and the remaining 26 strains $(18.18 \%)$ were non-typeable (Liu et al. 2018). Vadier in 2007, in France reported, 195 (42\%) S. aureus isolates as CP5, $45 \%$ CP8 and $13 \%$ were reported as other types (Vadier et al. 2007). In another study carried out in Argentina in 2009, of the total 118 S. aureus isolates collected from patients with osteomyelitis, 76 isolates (64\%) were capsular type 5 and 42 (36\%) were type 8 (21\%) (Lattar et al. 2009); similar results were observed in others studies (Fournier et al. 1987; Na'was et al. 1998). Pardo, analyzed 213 S. aureus strains that cause skin and soft-tissue infections obtained between 2004 and 2005 in Uruguay, and found that 85 isolates expressed CP8, only 1 expressed CP5 and 4 strains were nontypeable (Pardo 


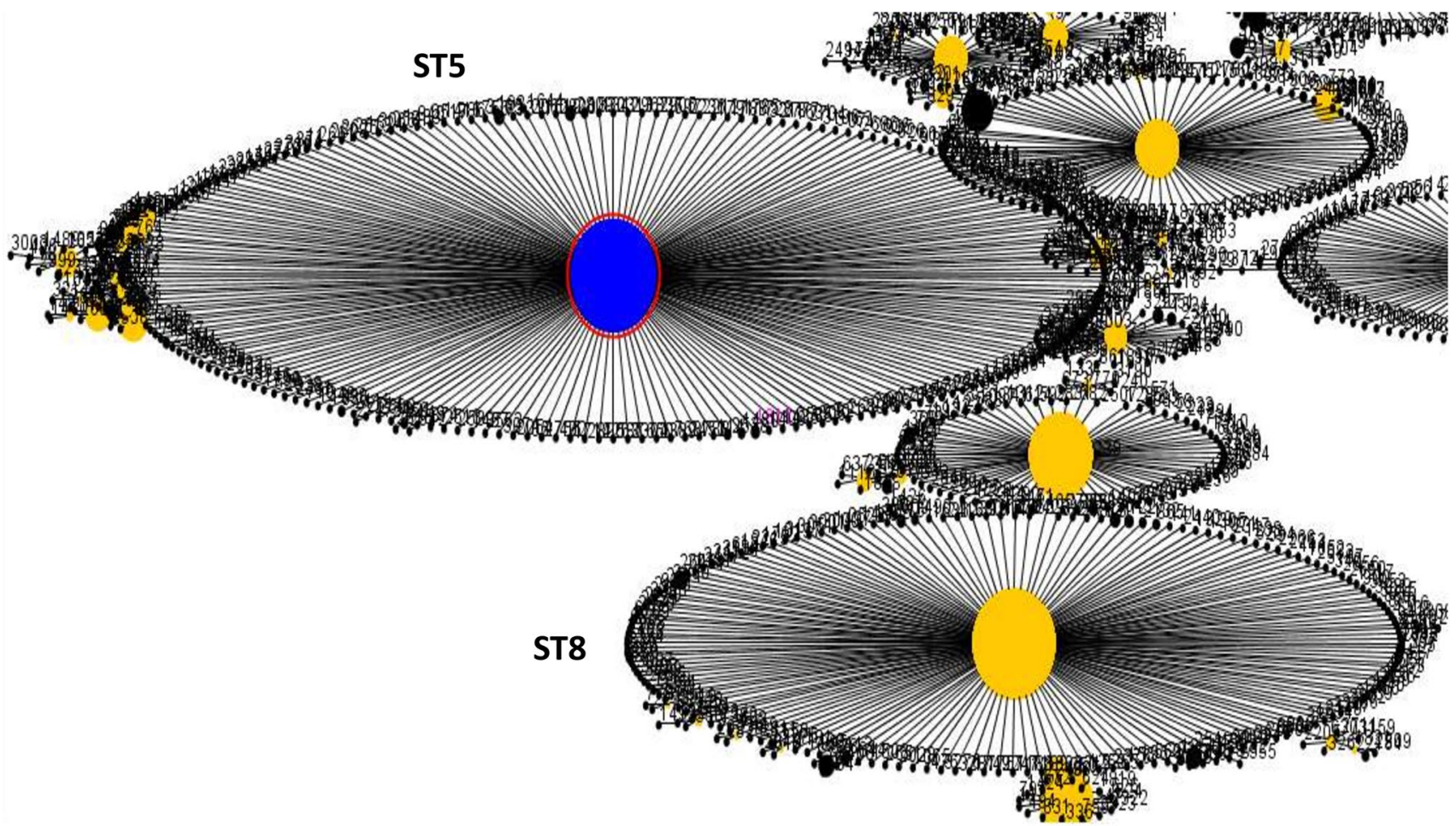

Fig. 3 Analysis of eBURST of the ST5 and ST8 clonal complex of MRSA. The relatedness between isolates in the MRSA MLST database that shared alleles at seven loci with the allelic profile of ST5 and ST8 is displayed as a dendrogram

et al. 2009). However, these results differ from our findings that showed the predominance of CP5. In another study, E. Sutter, studied 91 MRSA isolates during 2004-2005 and reported that type 5 and type 8 capsular genotypes were detected in only $58 \%$ of the strains, while the remaining $42 \%$ were either cap 5 or cap 8 , but did not express a capsule in vitro and reacted strongly with type 336PS antisera. The author suggested that the lack of capsule expression is common among clinical isolates of the most prevalent CA-MRSA clone, USA300 (Sutter et al. 2011). In contrast, our results showed that the strains analyzed descendants of the USA300 clone expressed the capsular genotype cap5.

These data are important for vaccine development because even though 80 to $90 \%$ of MRSA clinical isolates produce capsular polysaccharides type 5 or 8 ; a type $5 /$ type 8 capsular vaccine would be inadequate for 10 to $20 \%$ of the strains that are not typeable (Ma et al. 2004; O'Brien et al. 2000). Vadier, proposes that adding the 336 antigen to a types $5 / 8$ capsular vaccine should increase its coverage to $100 \%$ of all S. aureus infection isolates (Vadier et al. 2007). Although in our study not typeable $S$. aureus strains were not detected, this does not mean they cannot be circulating in our community, perhaps for their detection it would be necessary to analyze a bigger sample including $S$. aureus strains of carriers and methicillin sensitive. Because methicillin-sensitive $S$. aureus strains and strains isolated from healthy carriers have greater clonal diversity, and clonality is associated with capsular type (cap5, cap8 and not typeable).

A limited number of MRSA lineages have emerged from the transfer of SCCmec into successful methicillin-susceptible S. aureus (MSSA) clones. Using MLST typing Enright et al. demonstrated that MRSA clones evolved from five different groups of related genotypes or clonal complexes (CC), each arising from a distinct ancestral genotype (Enright et al. 2003). In this study, the ST36-MRSA-II-EMRSA-16 clone (cap8) was only found in isolates from 1999 to 2002 and in a single isolate from 2010. This was because clone EMRSA-16 (cap8) was present from 1999 to 2002 and was replaced in late 2002 by New York Japan clone (cap5) (Velazquez et al. 2004) and a sporadic isolate of EMRSA-16 was found in 2010. This clone is one of the dominant types of MRSA found in a UK hospital (Moore and Lindsay 2002) and is widely disseminated in Canada (Simor et al. 2002) and Greece (Aires de Sousa et al. 2003). The multiresistant ST5-MRSA-II-New York-Japan clone (cap5) was present in $89.7 \%$ of the MRSA strains analyzed; this clonal group was observed throughout the all study and is the predominant clone in clinical isolates in Mexico (Velazquez et al. 2013, 2004; Cornejo et al. 2010; Echaniz et al. 2006). A recent study showed the evolution of clonal complex 5 (CC5), that includes the ST5-MRSA-II-New York-Japan clone of Mexican isolates (Challagundla et al. 2018). This clone was initially described in New York and Tokyo, and is now widespread in USA and other parts of the 
world (Roberts et al. 1998; Aires de Sousa et al. 2003; Chung et al. 2004; McDougal et al. 2003). Strains belonging to the ST8-MRSA-IV-USA300 clone $(n=4)$ and ST247-MRSA-IIberian clone $(n=2)$, which also carry the cap 5 gene were present in two hospitals (H4 and H6) in 2008 and 2010, respectively. It has been reported that virulence gene profiles are strongly associated with $S$. aureus clonal lineages (Ferry et al. 2006; Thurlow et al. 2012).

\section{Conclusions}

This study showed that the prevalence of cap 5 in clinical isolates of MRSA is very high (93.5\%). The results obtained showed that the presence of cap 5 and cap 8 is closely associated with the clonal origin of the strains. Our results suggest the potential benefits of using $S$. aureus CP5 in the preparation of vaccines due to the prevalence of encapsulated strains in Mexican hospitals. The identification of the capsular genotypes of clinical isolates of MRSA is important information because capsular polysaccharides are part of potential vaccine formulations against $S$. aureus.

\begin{abstract}
Acknowledgements Mexico City, Instituto Nacional de Cancerología: Patricia Cornejo Juárez, Patricia Volkow Fernández, Consuelo Velazquez Acosta. Hospital de Pediatría del Centro Médico Nacional, Siglo XXI: María Guadalupe Miranda Novales, Fortino Solórzano Santos, Martha Camacho Velázquez. Instituto Nacional de Cardiología “Dr. Ignacio Chávez": Rosario Vázquez Larios, Eduardo Rivera Martínez, Ana María Hernández Dueñas. Nuevo León, Hospital San José Tec de Monterrey: Jacobo Ayala Aguilar, Claudia E. Guajardo Lara. Hospital Universitario “Dr J Eleuterio González”: Rosa María Robles Hinojosa, Facultad de Ciencias Biológicas: Licet Villarreal Treviño. Guadalajara, Hospital Civil "Fray Antonio Alcalde": María del Rayo Morfin Otero, Eduardo Rodríguez Noriega, Sergio Esparza Ahumada. Veracruz, Hospital Regional de Veracruz: Miguel Angel Ortíz Gil, Paul Mora Domínguez; Elsa Lilia Mendiola del Moral.
\end{abstract}

Funding This study was supported by a grant from the Instituto Nacional de Salud Pública (CISEI/1110). B. Rodríguez-Arvizu was a M.S. student at the Instituto Nacional de Salud Pública and was supported by Grant 486870 of CONACYT, México.

\section{Declarations}

Conflict of interest None declared.

Ethics approval and consent to participate This research was performed according to the principles expressed in the Declaration of Helsinki with approval from the Ethics Committee of the Instituto Nacional de Salud Publica; CI: 647.

\section{References}

Aires de Sousa M, de Lencastre H (2004) Bridges from hospitals to the laboratory: genetic portraits of methicillin-resistant
Staphylococcus aureus clones. FEMS Immunol Med Microbiol 40(2):101-111. https://doi.org/10.1016/S0928-8244(03)00370-5

Aires de Sousa M, Bartzavali C, Spiliopoulou I, Santos I, Crisostomo I, de Lencastre H (2003) Two international methicillin-resistant Staphylococcus aureus clones endemic in a university hospital in Patras, Greece. J Clin Microbiol 41(5):2027-2032. https:// doi.org/10.1128/JCM.41.5.2027-2032.2003

Challagundla L, Reyes J, Rafiqullah I, Sordelli DO, Echaniz-Aviles G, Velazquez-Meza ME, Castillo-Ramírez S, Fittipaldi N, Feldgarden M, Chapman SB, Calderwood MS, Carvajal LP, Rincon S, Hanson B, Planet PJ, Arias CA, Diaz L, Robinson DA (2018) Phylogenomic classification and the evolution of clonal complex 5 methicillin-resistant Staphylococcus aureus in the Western Hemisphere. Front Microbiol 9:1-14. https://doi.org/10.3389/ fmicb.2018.01901

Chung M, de Lencastre H, Matthews P, Tomasz A, Adamsson I, Aires de Sousa M, Camou T, Cocuzza C, Corso A, Couto I, Dominguez A, Gniadkowski M, Goering R, Gomes A, Kikuchi K, Marchese A, Mato R, Melter O, Oliveira D, Palacio R, SáLeão R, Santos Sanches I, Song JH, Tassios PT, Villari P, Multilaboratory Project Collaborators (2000) Molecular typing of methicillin- resistant Staphylococcus aureus by pulsed-field gel electrophoresis: comparison of results obtained in a multilaboratory effort using identical protocols and MRSA strains. Microb Drug Resist 6(3):189-198. https://doi.org/10.1089/mdr. 2000.6.189

Chung M, Dickinson G, de Lencastre H, Tomasz A (2004) International clones of methicillin-resistant Staphylococcus aureus in two hospitals in Miami, Florida. J Clin Microbiol 42(2):542-547. https://doi.org/10.1128/JCM.42.2.542-547.2004

Cornejo JP, Volkow FP, Sifuentes OJ, Echániz AG, Díaz GA, Velazquez AC, Bobadilla-DVM GMP, Velazquez MME (2010) Tracing the source of an outbreak of methicillin-resistant Staphylococcus aureus in a tertiary-care oncology hospital by epidemiology and molecular methods. Microb Drug Resist 16(3):203-208. https://doi.org/10.1089/mdr.2010.0048

Enright MC (2003) The evolution of a resistant pathogen the case of MRSA. Curr Opin Pharmacol 3(5):474-479. https://doi.org/10. 1016/s1471-4892(03)00109-7

Enright MC, Day NP, Davies CE, Peacock SJ, Spratt BG (2000) Multilocus sequence typing for characterization of methicillin-resistant and methicillin-susceptible clones of Staphylococcus aureus. J Clin Microbiol 38(3):1008-1015. https://doi.org/10.1128/JCM. 38.3.1008-1015.2000

Ferry T, Bes M, Dauwalder O, Meugnier H, Lina G, Forey F, Vandenesch F, Etienne J (2006) Toxin gene content of the Lyon methicillin-resistant Staphylococcus aureus clone compared with that of other pandemic clones. J Clin Microbiol 44(7):2642-2644. https:// doi.org/10.1128/JCM.00430-06

Fournier JM, Bouvet A, Boutonnier A, Audurier A, Goldstein F, Pierre J, Bure A, Lebrun L, Hochkeppel HK (1987) Predominance of capsular polysaccharide type 5 among oxacillin-resistant Staphylococcus aureus. J Clin Microbiol 25(10):1932-1933. https://doi. org/10.1128/jcm.25.10.1932-1933.1987

Haddad O, Merghni A, Elargoubi A, Rhim H, Kadri Y, Mastouri M (2018) Comparative study of virulence factors among methicillin resistant Staphylococcus aureus clinical isolates. BMC Infect Dis 18(1):560. https://doi.org/10.1186/s12879-018-3457-2

Harada D, Nakaminami H, Miyajima E, Sugiyama T, Sasai N, Kitamura Y, Tamura T, Kawakubo T, Noguchi N (2018) Change in genotype of methicillin-resistant Staphylococcus aureus (MRSA) affects the antibiogram of hospital-acquired MRSA. J Infect Chemother 24(7):563-569. https://doi.org/10.1016/j.jiac.2018. 03.004

Inouea M, Yonemurab T, Baber J, Shojid Y, Aizawa M, Coopere D, Eidene J, Grubere W, Jansene K, Andersone A, Gurtmane A 
(2018) Safety, tolerability, and immunogenicity of a novel 4-antigen Staphylococcus aureus vaccine (SA4Ag) in healthy Japanese adults. Hum Vacc Immunother 14(11):2682-2691. https://doi.org/ 10.1080/21645515.2018.1496764

Kateete DP, Bwanga F, Seni J, Mayanja R, Kigozi E, Mujuni B, Ashaba FK, Baluku H, Najjuka CF, Källander K, Rutebemberwa E, Asiimwe BB, Joloba ML (2019) CA-MRSA and HAMRSA coexist in community and hospital settings in Uganda. Antimicrob Resist Infect Control 8:94. https://doi.org/10.1186/ s13756-019-0551-1

Keinhörster D, George SE, Weidenmaier C, Wolz C (2019) Function and regulation of Staphylococcus aureus wall teichoic acids and capsular polysaccharides. Int J Med Microbiol 309(6):15133. https://doi.org/10.1016/j.ijmm.2019.151333

Khalid M, Junejo S, Mir F (2018) Invasive community acquired methicillin-resistant Staphylococcal aureus (CA-MRSA). Infect Child J Coll Physicians Surg Pak 28(9):174-177. https://doi.org/10. 29271/jcpsp.2018.09.S174

Lakhundi S, Zhang K (2018) Methicillin resistant Staphylococcus aureus: molecular characterization, evolution, and epidemiology. Clin Microbiol Rev 31(4):e00020-e118. https://doi.org/10.1128/ CMR.00020-18

Lattar SM, Tuchscherr LP, Caccur RL, Centrón D, Becker K, Alonso CA, Barberis C, Miranda G, Buzzola FR, von Eiff C, Sordelli DO (2009) Capsule expression and genotypic among Staphylococcus aureus isolates from patients with chronic or acute osteomyelitis. Infect Immun 77(5):1968-1975. https://doi.org/10.1128/IAI. 01214-08

Liu B, Sun H, Pan Y, Zhai Y, Cai T, He D, Liu J, Yuan L, Hu G (2018) Prevalence resistance pattern, and molecular characterization of Staphylococcus aureus isolates from healthy animals and sick populations in Henan Province, China. Gut Pathog 10:31. https:// doi.org/10.1186/s13099-018-0254-9

Ma J, Cocchiaro J, Lee JC (2004) Evaluation of serotypes of Staphylococcus aureus strains used in the production of a bovine mastitis bacterin. J Dairy Sci 87(1):178-182. https://doi.org/10.3168/jds. S0022-0302(04)73156-2

Echaniz AG, Velazquez MME, Aires de Sousa M, Morfín OR, Rodríguez NE, Carnalla BMN, Esparza AS, de Lencastre H (2006) Molecular characterization of a dominant methicillin-resistant Staphylococcus aureus (MRSA) clone in a Mexican hospital (1999-2003). Clin Microbiol Infect 12(1):12-28. https://doi.org/ 10.1111/j.1469-0691.2005.01283.x

McDougal LK, Steward CD, Killgore GE, Chaitram JM, McAllister SK, Tenover FC (2003) Pulsed-field gel electrophoresis typing of oxacillin-resistant Staphylococcus aureus isolates from the United States: establishing a national database. J Clin Microbiol 41(11):5113-5120. https://doi.org/10.1128/JCM.41.11.51135120.2003

Melles DC, Taylor KL, Fattom AI, van Belkum A (2008) Serotyping of Dutch Staphylococcus aureus strains from carriage and infection. FEMS Immunol Med Microbiol 52(2):287-292. https://doi.org/ 10.1111/j.1574-695X.2008.00376.x

Mohamed N, Timofeyeva Y, Jamrozy D, Rojas E, Hao L, Silmon de Monerri NC, Hawkins J, Singh G, Cai B, Liberator P, Sebastian S, Donald RGK, Scully IL, Jones H, Creech CB, Thomsen I, Parkhill J, Peacock SJ, Jansen KU, Holden MTG, Anderson AS (2019) Molecular epidemiology and expression of capsular polysaccharides in Staphylococcus aureus clinical isolates in the United States. PLoS ONE 14(1):e0208356. https://doi.org/10.1371/journ al.pone. 0208356

Moore P, Lindsay J (2002) Molecular characterization of the dominant UK methicillin resistant Staphylococcus aureus strain, EMRSA15 and EMRSA-16. J Med Microbiol 51(6):516-521. https://doi. org/10.1099/0022-1317-51-6-516
Na'was T, Hawwari A, Hendrix E, Hebden J, Edelman R, Martin M, Campbell W, Naso R, Schwalbe R, Fattom AI (1998) Phenotypic and genotypic characterization of nosocomial Staphylococcus aureus isolates from trauma patients. J Clin Microbiol 36(2):414 420. https://doi.org/10.1128/JCM.36.2.414-420.1998

O'Brien CN, Guidry AJ, Fattom A, Shepherd S, Douglass LD, Westhoff DC (2000) Production of antibodies to Staphylococcus aureus serotypes 5, 8, and 336 using poly (DL-lactide-co-glycolide) microspheres. J Dairy Sci 83(8):1758-1766. https://doi.org/10. 3168/jds.S0022-0302(00)75046-6

Oliveira DC, de Lencastre H (2002) Multiplex PCR strategy for rapid identification of structural types and variants of the mec element in methicillin resistant Staphylococcus aureus. Antimicrob Agents Chemother 46(7):2155-2161. https://doi.org/10.1128/AAC.46.7. 2155-2161.2002

Pardo L, Machado V, Mollerach M, Mota MI, Tuchscherr LP, Gadea P, Gardella N, Sordelli DO, Vola M, Schelotto F, Varela G (2009) Characteristics of community-associated methicillin-resistant Staphylococcus aureus (CA-MRSA) strains Isolated from skin and soft-tissue infections in Uruguay. Int J Microb 2009:472126. https://doi.org/10.1155/2009/472126

Park S, Gerber S, Lee JC (2014) Antibodies to Staphylococcus aureus serotype 8 capsular polysaccharide react with and protect against serotype 5 and 8 isolates. Infect Immun 82(12):5049-5055. https://doi.org/10.1128/IAI.02373.14

Roberts RB, de Lencastre A, Eisner W, Severina EP, Shopsin B, Kreiswirth BN, Tomasz A (1998) Molecular epidemiology of methicillin resistant Staphylococcus aureus in 12 New York hospitals. J Infect Dis 178(1):164-171. https://doi.org/10.1086/515610

Rozemeijer W, Fink P, Rojas E, Jones CH, Pavliakova D, Giardina P, Murphy E, Liberator P, Jiang Q, Girgenti D, Peters RP, Savelkoul PH, Jansen KU, Anderson AS, Kluytmans J (2015) Evaluation of approaches to monitor Staphylococcus aureus virulence factor expression during human disease. PLoS ONE 10(2):e0116945. https://doi.org/10.1371/journal.pone.0116945

Sau S, Bhasin N, Wann ER, Lee JC, Foster TJ, Lee CY (1997) The Staphylococcus aureus allelic genetic loci for serotype 5 and 8 capsule expression contain the type-specific genes flanked by common genes. Microbiol 143:2395-2405. https://doi.org/10. 1099/00221287-143-7-2395

Simor A, Ofner-Agostini M, Bryce E, McGeer A, Paton S (2002) Laboratory characterization of methicillin-resistant Staphylococcus aureus in Canadian hospitals: results of 5 years of national surveillance, 1995-1999. J Infect Dis 186(5):652-660. https://doi. org/10.1086/342292

Sutter DE, Summers AM, Keys CE, Taylor KL, Frasch CE, Braun LE, Fattom AI, Bash MC (2011) Capsular serotype of Staphylococcus aureus in the era of community-acquired MRSA. FEMS Immunol Med Microbiol 63(1):16-24. https://doi.org/10.1111/j.1574-695X. 2011.00822.x

Tenover FC, Arbeit RD, Goering RV, Mickelsen PA, Murray BE, Persin DH, Swaminathan B (1995) Interpreting chromosomal DNA restriction patterns produced by pulsed-field gel electrophoresis: criteria for bacteria strain typing. J Clin Microbiol 33(9):22332239. https://doi.org/10.1128/jcm.33.9.2233-2239.1995

Thurlow LR, Joshi GS, Richardson AR (2012) Virulence strategies of the dominant USA300 lineage of community-associated methicillin-resistant Staphylococcus aureus (CA-MRSA). FEMS Immunol Med Microbiol 65(1):5-22. https://doi.org/10.1111/j.1574-695X. 2012.00937.X

Udo EE, Boswihi SS, Mathew B, Noronha B, Verghese T, Al-Jemaz A, Saqer F (2020) Emergence of methicillin-resistant Staphylococcus aureus belonging to clonal complex 15 (CC15-MRSA) in Kuwait hospitals. Infect Drug Resist 13:617-626. https://doi.org/ 10.2147/IDR.S237319 
Velazquez MME, Aires de Sousa M, Echániz AG, Solórzano SF, Miranda NG, Silva SJ, de Lencastre H (2004) Surveillance of methicillin-resistant Staphylococcus aureus in a pediatric hospital in Mexico City during a 7-year period (1997 to 2003): clonal evolution and impact of infection control. J Clin Microb 42(8):38773880. https://doi.org/10.1128/JCM.42.8.3877-3880.2004

Velazquez MME, Hernández SM, Contreras CJF, Pérez CP, Villarreal TL (2013) Surveillance of methicillin-resistant Staphylococcus aureus causing nosocomial infections in five medical centers of Monterrey, Nuevo Leon, Mexico from 2005-2009. Arch Med Res 44(7):570-657. https://doi.org/10.1016/j.arcmed.2013.09.001

Verdier I, Durand G, Bes M, Taylor KL, Gerard L, Vandenesch F, Fattom AI, Etienne J (2007) Identification of the capsular polysaccharides in Staphylococcus aureus clinical isolates by PCR and agglutination tests. J Clin Microbiol 45(3):725-729. https:// doi.org/10.1128/JCM.01572-06

Visansirikul S, Kolodziej SA, Demchenko AV (2020) Staphylococcus aureus capsular polysaccharides: a structural and synthetic perspective. Org Biomol Chem 18(5):783-798. https://doi.org/ $10.1039 / \mathrm{c} 9 \mathrm{ob} 02546 \mathrm{~d}$

Publisher's Note Springer Nature remains neutral with regard to jurisdictional claims in published maps and institutional affiliations. 